\title{
A Planar UWB Antenna with Switchable Single/Double Band-Rejection Characteristics
}

\author{
Vahid SHARBATI, Pejman REZAEI, Mohammad M. FAKHARIAN \\ Dept. of Electrical and Computer Engineering, Semnan University, Semnan, Iran \\ v.sharbati@semnan.ac.ir,prezaei@semnan.ac.ir,m fakharian@semnan.ac.ir \\ Manuscript received September 1, 2015
}

\begin{abstract}
In this paper, a reconfigurable antenna with capability to operate in the ultrawideband (UWB) mode from 2.85 to $14.4 \mathrm{GHz}$ with switchable notch bands of 3.25-4.26 GHz, 5.1-5.9 GHz or 7.1-7.8 GHz, is presented. The proposed antenna has a simple configuration and compact size of $17 \times 14 \mathrm{~mm}^{2}$. To make the band-notches, three methods (methods of slot antenna, parasitic patches and backplane structure) are used. To achieve the reconfigurability, three PIN diodes are placed on the proposed antenna. A PIN diode is inserted over the L-shaped parasitic element and the rectangular patch, another one is placed between the two parasitic elements on the ground plane, and other across the square ring-shaped slot, respectively. Antenna performance can be changed by adjusting the status of the PIN diodes that make the bandnotches in applications bands (WLAN, WiMAX/C-band and $X$-band). Good group delay and monopole-like radiation pattern characteristics are achieved in the frequency band of interest. The antenna performance both by simulation and by experiment indicates that it is suitable and a good candidate for UWB applications.
\end{abstract}

\section{Keywords}

Reconfigurable antenna, ultrawideband (UWB), band-rejection, single, double

\section{Introduction}

Ultrawideband (UWB) technology is now becoming used in a variety of applications such as positioning systems, short-range communications, and radars. This is because this technology offers advantages of multipath propagation performance, large channel capacity, and potential for ultralow-power implementation of transmittingonly devices [1]. Especially, an UWB antenna should be capable of operating over an ultra-wide bandwidth as determined by the Federal Communications Commission (FCC), that is, $3.1-10.6 \mathrm{GHz}$ [2]. Despite the benefits of UWB systems, there are many narrowband systems which severely interfere with the UWB communication system, such as WiMAX (3.3-3.6 GHz), C-band (3.7-4.2 GHz),
WLAN (5.15-5.35 GHz and 5.725-5.825 GHz), HIPERLAN/2 (5.47-5.725 GHz), and X-band (7.25-7.75 GHz). Therefore, UWB antennas with band-notched characteristics to filter this potential interference are desirable. Recently, the various techniques have been applied to design UWB antennas with band-notch characteristics [3-11]. These include embedment of different slots on the ground plane or on the radiating patch, use of parasitic elements patches, etching of split-ring resonators, use of tuning stubs, meandering of ground plane and so on [3-5]. For example, UWB slot antennas with reconfigurable bandnotch characteristics are proposed in [6], [7]. Also in [8], [9], notch functions are done by the parasitic patches. A slotted patch has been designed to reject WLAN band [10] and defected ground structure (DGS) [11] are other approaches used for band-notch functions.

In this paper, a compact switchable antenna is proposed for UWB applications. First, the proposed antenna generates UWB $(2.85-14 \mathrm{GHz})$ and then the antenna function can be changed by switches that make the notch bands in application bands (WiMAX/C-band satellite, WLAN and X-band). The UWB characteristics are obtained by embedded square ring-shaped slot on the patch and a parasitic element that is attached to the patch. To achieve the desired frequency reconfigurability, three switches are placed on the proposed antenna. The first switch is embedded over the L-shaped parasitic element and the rectangular patch to filter the WiMAX and C-band satellite. The second switch is located between the two parasitic elements on the ground plane to filter the WLAN band. The third switch is embedded among the square ring shaped-slot to filter the X-band. In comparison with the presented antennas in [3-14], the proposed antenna is compact and uses varied and simple methods to generate single or double notch bands.

\section{Antenna Design and Configuration}

The proposed antenna is printed on an FR4 substrate, with dimensions of $17 \times 14 \times 0.8 \mathrm{~mm}^{3}$, permittivity 4.4 , and loss tangent of 0.02 . Figure 1 shows the schematic and dimensions of the proposed antenna. To achieve 50- $\Omega$ characteristic impedance, the length and width of the feed- 


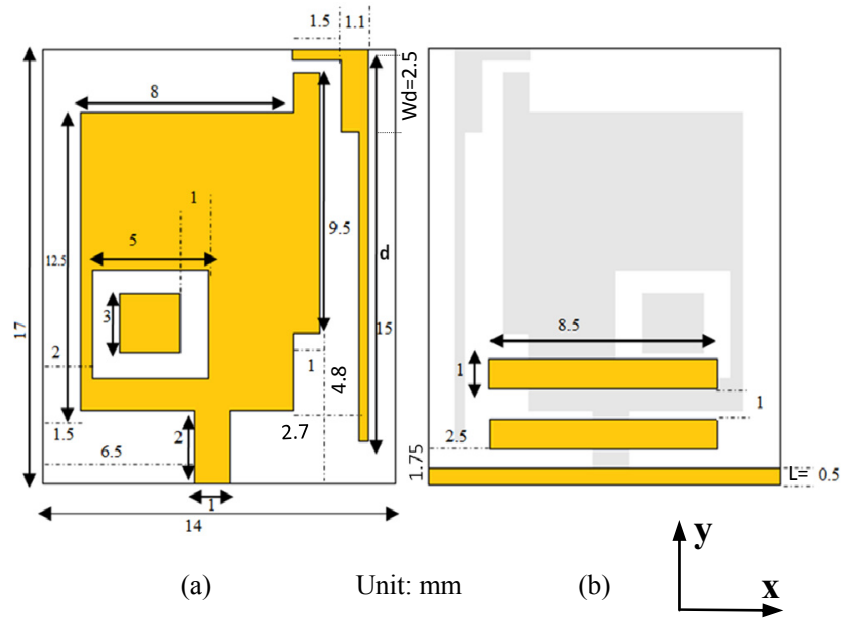

Fig. 1. Geometry of the proposed microstrip monopole antenna: a) top view, b) bottom view.

line are chosen as 2 and $1 \mathrm{~mm}$, respectively. The antenna consists of a defected-rectangular radiation patch with square ring-shaped slot on the patch and a parasitic element that is attached to it. An L shaped parasitic elements are placed in right of the rectangular patch. Also two rectangular parasitic elements embedded on the ground plane. All simulations are done using Ansoft HFSS ver. 11.

\subsection{UWB Antenna Design}

This section details the UWB structure. This antenna generates the band of $2.85-14.4 \mathrm{GHz}$ that is suitable for UWB applications. Figure 2 shows the structure of the designed antenna in four steps with comparisons among return loss characteristics for these quadripartite steps used for UWB performance simulation studies. As shown in Fig. 2, in the first step, a simple rectangular patch is designed, in the second step, a rectangular parasitic element in the right of the patch is added, in the third step, a square ring-shaped slot is embedded on the patch that plays important role to achieve the UWB, and finally the proposed antenna is shown in the fourth step. The L-shaped parasitic element and two rectangular parasitic elements have low effect for generating the band of UWB.

The position of square ring slot on the rectangular patch is very critical to achieve the UWB band. Figure 3

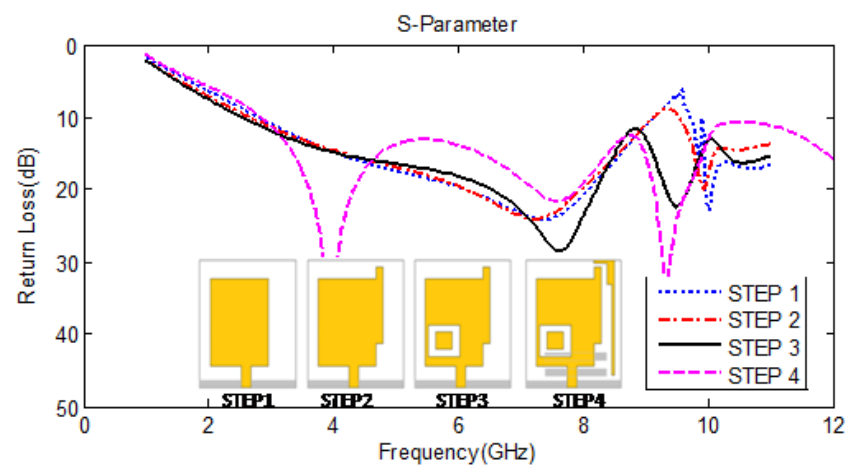

Fig. 2. Simulated return loss characteristics for the four steps of the antenna design.

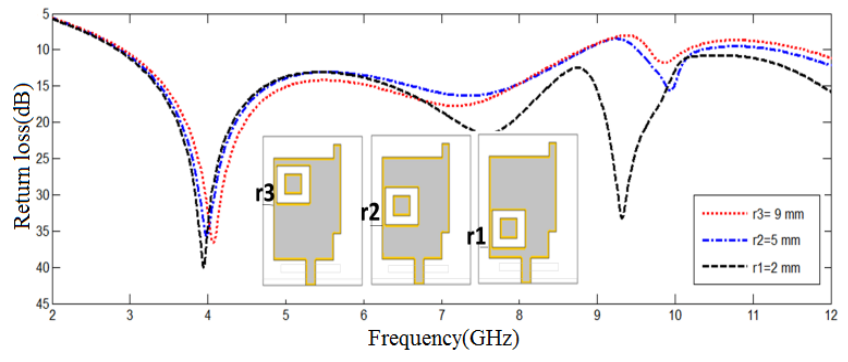

Fig. 3. Simulated return loss of proposed antenna for three positions of square ring-shaped slot on the patch in $\mathrm{y}$-axis.

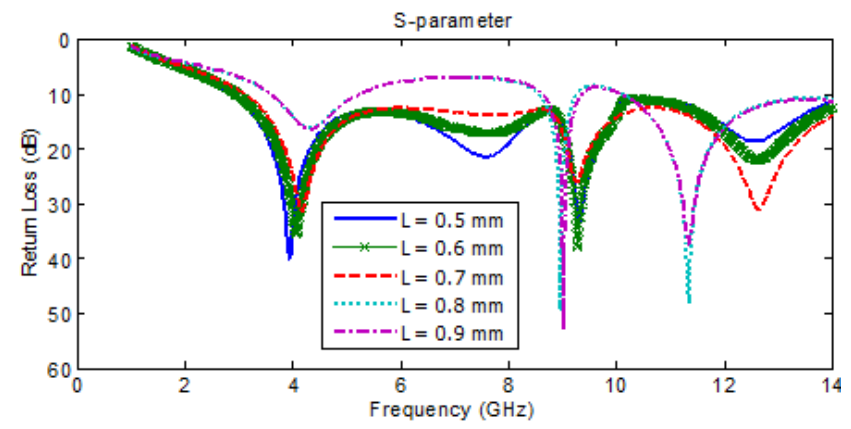

Fig. 4. Simulated return loss characteristics of the UWB antenna with different values of $\mathrm{L}$.

shows simulated return loss of the proposed antenna for three positions of square ring-shaped slot on the patch in y-axis.

Also the value of $\mathrm{L}$ in the ground plane is critical to generate the band of UWB. Figure 4 shows the curve of simulated return loss characteristics of the antenna with distinctive values of $\mathrm{L}$ for the parametric analysis and optimization of designs. It is found that by reducing the value of $\mathrm{L}$, the bandwidth increases from 2.85 to over $14 \mathrm{GHz}$.

\subsection{Switchable Band-Notched UWB Antenna}

The UWB antenna that was introduced in the previous section can be applied as a single or double bandnotched UWB antenna in the bands of WiMAX/C-band, WLAN and X-band. In this research, the switch for reconfigurability is a PIN diode model (HPND-4005).

Figure 5(a) and (b) show the fabricated prototypes of the proposed antenna. $3 \mathrm{D}$ view of the proposed antenna is shown in Fig. 6. As shown in this figure, three PIN diodes are used as switches. Three horizontally DC lines are etched to connect the PIN diodes to biasing sources through the stubs in the ground plane.

The DC lines with $0.1 \mathrm{~mm}$ width are designed and the vias are used to connect and fed the PIN diodes on the top layer to DC line of the ground plane. The states of PIN diodes Sw1, Sw2 and Sw3 are controlled by a DC bias line printed on the back side of the substrate and connected to three external voltage sources V1, V2 and V3. The three DC bias lines are connected by means of wires to the three independent outputs of an external control unit. The general ground of the control unit is connected by means of 


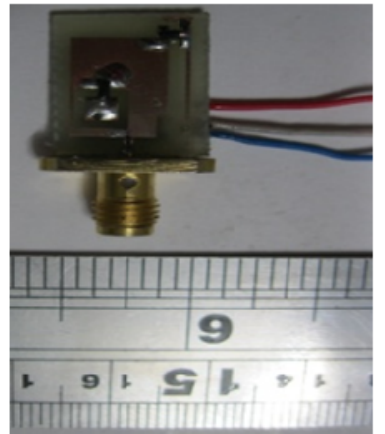

(a)

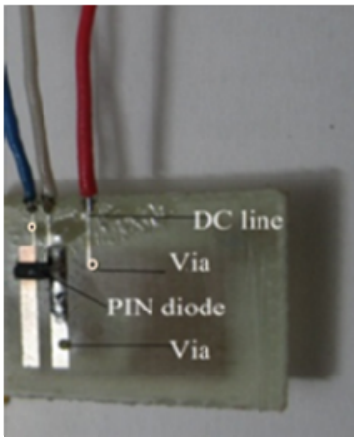

(b)
Fig. 5. Fabricated prototypes of the proposed antenna: (a) top view, (b) bottom view.

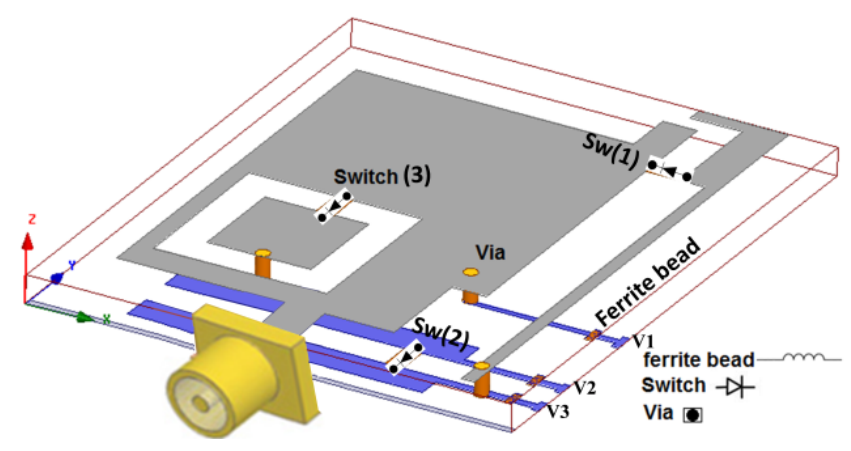

Fig. 6. 3D view of the DC lines and pin diodes of the proposed antenna.

a wire to the antenna ground plane at vias. The control unit can provide one of the three DC voltages, $-1 \mathrm{~V}, 0 \mathrm{~V}$, or $+1 \mathrm{~V}$, at each of the output ports. In order to simulate the switches in HFSS, metal bridge model and pin-diode equivalent circuit are designed. According to the data sheet of PIN diode, when the PIN diode is ON-state the pindiode equivalent circuit is with a series inductance of $0.15 \mathrm{nH}$ and resistance of $4.7 \Omega$, and when the PIN diode is $\mathrm{OFF}$, there is one resistance of $5 \mathrm{k} \Omega$ parallel with a capacitance of $0.017 \mathrm{pF}$. Also, in the metal bridge model the presence of the metal bridge depicts that the switch state is $\mathrm{ON}$; vice versa, the absence of the metal bridge depicts that the switch state is OFF in simulation. The dimension of the ideal switches is selected $1 \times 0.5 \mathrm{~mm}^{2}$ to be close to the actual dimension of a PIN diode switch.

In this section, to discuss the mechanism of the dual band-rejected filtering properties, an equivalent circuit model of the proposed dual band-notched UWB antenna is presented. Figure 7 shows the equivalent circuit of UWB patch antenna with square ring-shaped slot. The proposed antenna is designed by using equivalent circuit of step discontinuity, rectangular patch antenna and square ringshaped slot for notch. In the proposed antenna two steps are used. In this model the patch cavity is modelled as a parallel RLC circuit, while the probe inductance is modelled as a series inductor. A parallel LC circuit shows the notch characteristic. When a notch is incorporated into the patch, the resonance features change. An equivalent circuit for a switch branch is modelled as a parallel LC circuit. The backplane stubs can be represented by the capacitance network shown in Fig. 7. For microstrip lines, the capacitances per unit length of line can be obtained numerically or by approximate quasi-static techniques [15]. The circuit parameters of $C_{\mathrm{n} 2}, C_{\mathrm{n}}$, and $L_{\mathrm{n} 2}$, are the distributed capacitance, resistance of the line, distributed inductance, respectively. As can be seen in Fig. 7, the equivalent circuit of the square ring-shaped slot corresponds to the LC equivalent circuit model of a bandstop filter. If $\mathrm{R} 1$ is equal to $50 \Omega$ in the RLC tank circuit, then the values of $C, L$ and $L_{\mathrm{p}}$ at each operating frequency are given as:

$$
\begin{gathered}
C=\frac{2 W \varepsilon_{\mathrm{r}}}{L h \omega_{0}^{2}}, \\
L=\frac{1}{C \omega_{0}^{2}}, \\
L_{\mathrm{p}}=\frac{W L_{\mathrm{n}}}{L}, \\
\omega_{0}=\frac{1}{\sqrt{L_{\mathrm{T}} C_{\mathrm{T}}}}
\end{gathered}
$$

where $h$ is the substrate height, $W$ is the feed width, $C_{\mathrm{T}}$ is the sum of the capacitors $\left(C_{\mathrm{n}}\right.$ and $\left.C_{\mathrm{n} 2}\right), L_{\mathrm{T}}$ is the sum of the distributed inductances $\left(L_{\mathrm{n}}\right.$ and $\left.L_{\mathrm{n} 2}\right)$. The back plane can be represented by the capacitance network shown in Fig. 7.

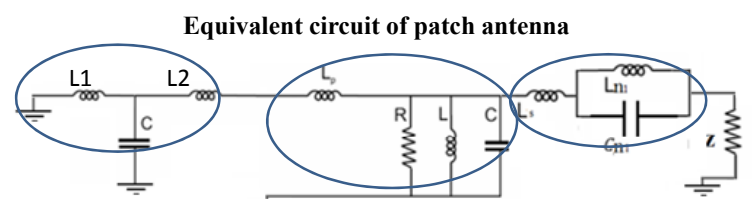

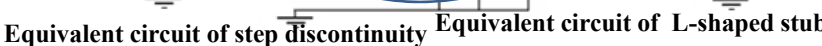
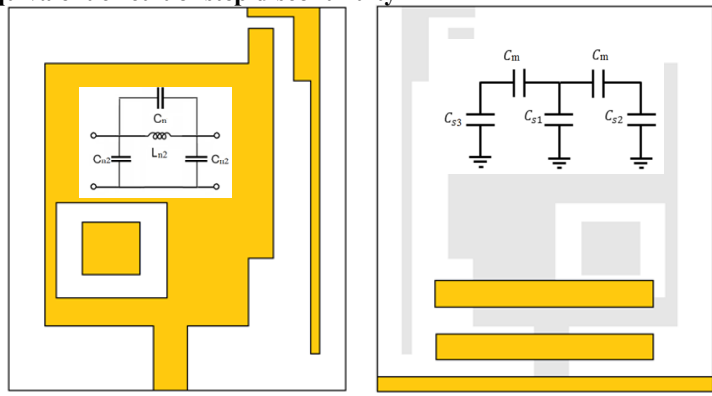

Fig. 7. Equivalent circuit of the proposed antenna

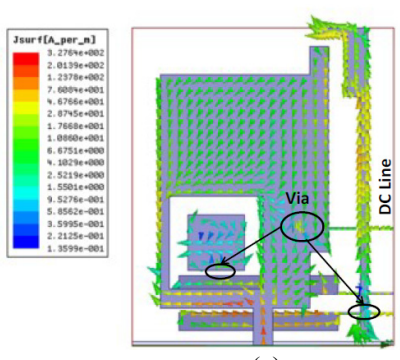

(a)

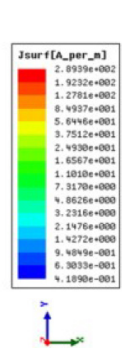

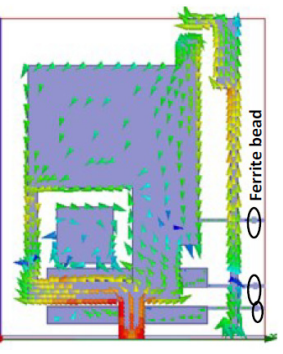

(b)
Fig. 8. Simulated current distribution of UWB mode at $7 \mathrm{GHz}$ (a) without and (b) with ferrite beads. 


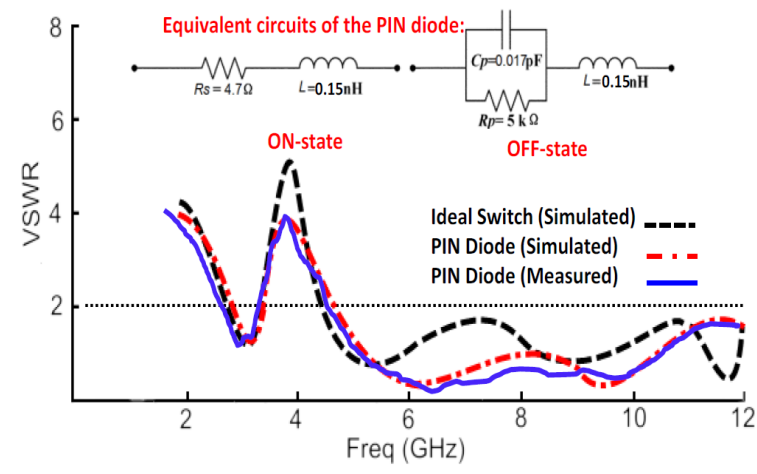

Fig. 9. The equivalent circuit of the PIN diode with the comparison between curves of simulated and measured VSWR results.

\begin{tabular}{|c|c|c|c|c|c|c|}
\hline \multirow{5}{*}{ State } & \multicolumn{3}{|c|}{ Diodes } & \multicolumn{3}{c|}{ Voltage(V) } \\
\cline { 2 - 7 } & SW1 & SW2 & SW3 & V1 & V2 & V3 \\
\cline { 2 - 7 } & ON & OFF & OFF & 0 & 0 & 1 \\
\cline { 2 - 7 } & OFF & ON & OFF & 0 & 1 & 0 \\
\cline { 2 - 7 } & OFF & OFF & ON & 1 & 0 & 0 \\
\cline { 2 - 7 } & ON & ON & OFF & -1 & 1 & 0 \\
\cline { 2 - 7 } & ON & OFF & ON & 0 & -1 & 1 \\
\cline { 2 - 7 } & OFF & ON & ON & 1 & 0 & -1 \\
\hline
\end{tabular}

Tab. 1. Diode states and associated de voltages for different bands-rejection.

The isolation of DC bias lines from the RF signal is performed by inductor of $70 \mathrm{nH}$ as ferrite beads. Therefore, in the proposed antenna three ferrite beads are simulated as RF chokes for reducing the effects of the DC biasing on the antenna performance. Figure 8 describes the current distribution with and without ferrite beads that is added along the vertical bias lines. As shown in Fig. 8, when the ferrite beads are added on the DC lines, the effect of bias line on the antenna performance is decreased. The PIN diode equivalent circuit is described in Fig. 9. This figure shows a comparison among curves of the simulated VSWR of ideal switch (Sw.1), the equivalent circuit of PIN diode, and the measured result.

Table 1 shows the ON and OFF states of the diodes for different band-notch of the antenna. For example, to operate the antenna in dual band-rejection (WiMAX and WLAN), it is required to turn ON diodes Sw.1 and Sw.2, so the DC voltages $\mathrm{V} 1$ set to $-1 \mathrm{~V}, \mathrm{~V} 2$ to $1 \mathrm{~V}$ and $\mathrm{V} 3$ to $0 \mathrm{~V}$.

\section{Result and Discussions}

In designing the antenna, the notched frequency can be empirically predicted by the following formula [5]. By adjusting the dimensions of $d=\left(L_{\mathrm{p}}+W_{\mathrm{d}}\right)$ in the L-shaped stubs placed on the right of the patch, the center frequencies of the lower and higher notched band can be controlled independently.

$$
f_{\text {notch } 1}=\frac{c}{4 L_{\mathrm{p}} \sqrt{\frac{1+\varepsilon_{\mathrm{r}}}{2}}} .
$$

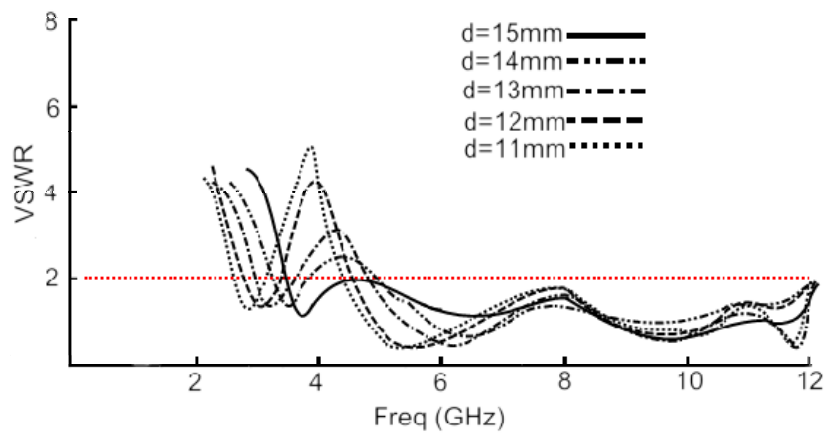

(a)

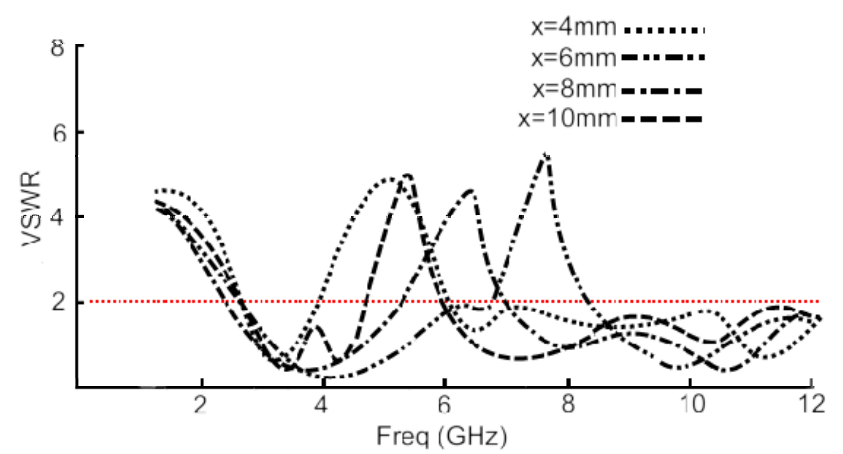

(b)

Fig. 10. Simulated VSWR characteristics of the switchable band-notched UWB antenna: a) with different values of $d, \mathrm{~b}$ ) different positions of switch (Sw. 2).

In (5), $c$ is the speed of the light, $\varepsilon_{\mathrm{r}}$ is the dielectric constant, and $L_{\mathrm{p}}\left(L_{\mathrm{p}}=d-W_{\mathrm{d}}\right)$ is the length of the stub. According to (1), the calculated notched frequency is 3.651 GHz. The simulated notched frequency is $3.75 \mathrm{GHz}$.

Figure 10(a) shows the simulated VSWR of the bandnotched UWB antenna for different values of $d$ in the L-shaped stubs to generate the band- rejection of WiMAX/C-band. It can be seen, when the length of $d$ changes from 11 to $15 \mathrm{~mm}$, the notched band moves to the lower frequency. The position of the switch to achieve the band-rejection in WLAN is very critical. Figure 10(b) presents the simulated VSWR curves of the position of switch that is changed on the $\mathrm{x}$-axis to generate band-rejection of WLAN. Figure 11(a) and (b) show the measured and simulated VSWR of the proposed antenna for different states of the switches. When Sw.1 is ON, the band-rejection in the $3.25-4.26 \mathrm{GHz}$ (WiMAX band and C-band satellite) is generated. When Sw.2 is ON, the band rejection of $5-5.9 \mathrm{GHz}$ (WLAN) is observed. Also when Sw.3 is $\mathrm{ON}$, the band rejection of $7-7.7 \mathrm{GHz} \mathrm{X}$-band is obtained. Also when the Sw. 1 and Sw. 2 are ON, dual bandrejections of 3.3-4.25 GHz and 4.8-5.6 GHz are generated. When the switches of Sw.1 and Sw. 3 are ON, dual bandrejection of $3.3-4.2 \mathrm{GHz}$ and $6.9-7.8 \mathrm{GHz}$ are created. Finally, when the Sw.2 and Sw. 3 are ON, dual band-rejections of 4.9-5.9 GHz and 7-7.8 GHz are obtained.

Figures 12(a), (b) and (c) show the simulated E-plane (xz-plane) and H-plane (yz-plane) at three different spot frequencies, when Sw. 1 is ON $(3.5 \mathrm{GHz}), \mathrm{Sw} .2$ is ON $(5.5 \mathrm{GHz})$ and $\mathrm{Sw} .3$ is $\mathrm{ON}(7.5 \mathrm{GHz})$, respectively. Figure $12(\mathrm{~d})$ shows the simulated and measured radiation 


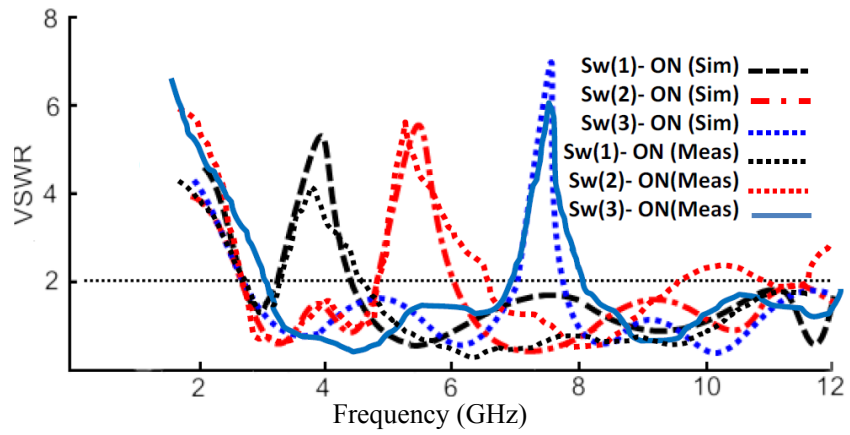

(a)

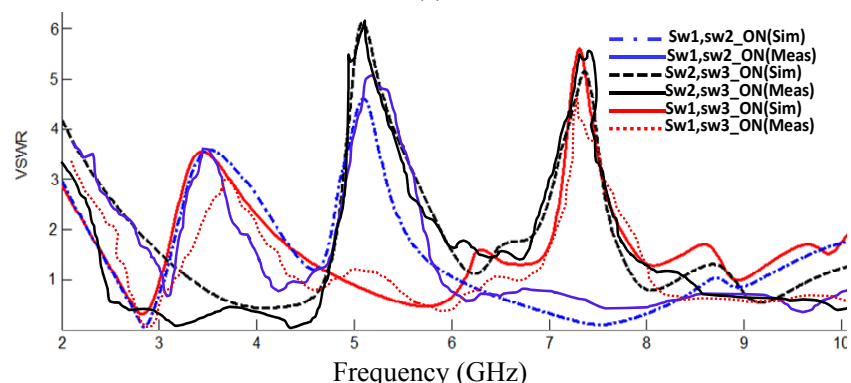

(b)

Fig. 11. Simulated VSWR characteristic for states of the switches when, a) single switch is ON-state, b) two switches are $\mathrm{ON}$-state.
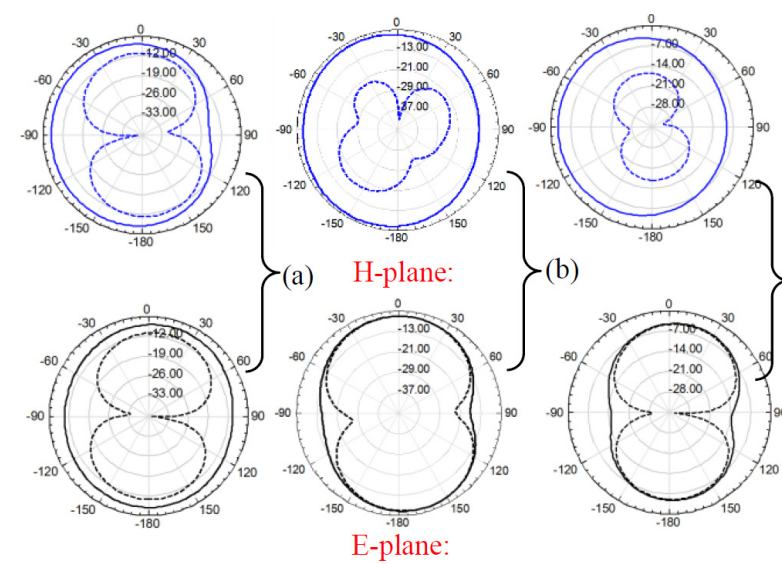

(b)
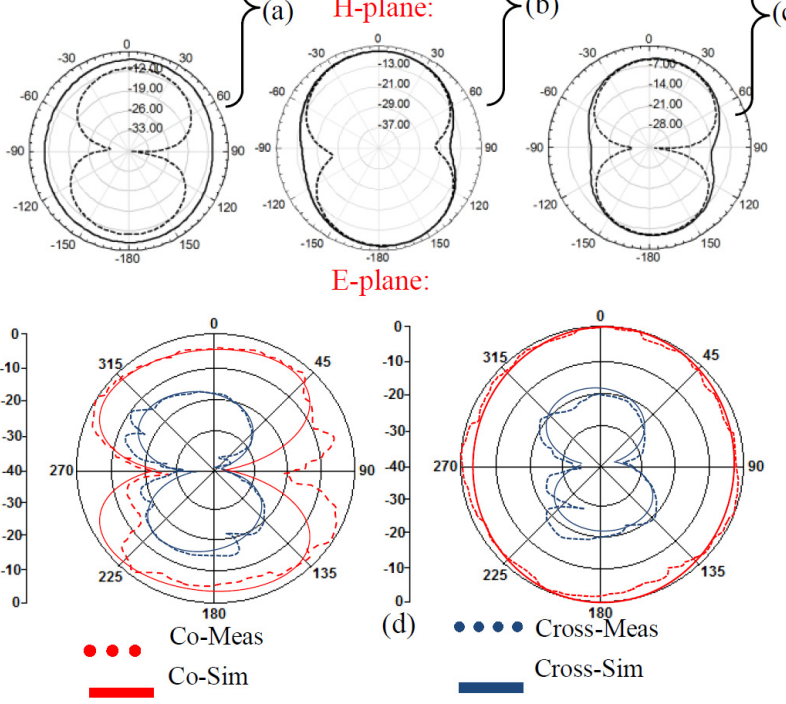

Fig. 12. Simulated $H$ and E-plane radiation patterns of the proposed antenna when: (a) Sw.1 is ON-state at $3.5 \mathrm{GHz}$, (b) Sw.2 is ON-state at $5.5 \mathrm{GHz}$ and (c) Sw.3 is ON-state at $7.5 \mathrm{GHz}$, and (d) measured $\mathrm{H}$ and Eplane UWB mode at $7.5 \mathrm{GHz}$.

patterns of the antenna in the UWB mode. It can be seen in the figure, there is a reasonable agreement between measurements and simulations in both planes.

The gains of switchable single/tri-band antennas are measured independently using gain comparison method



Fig. 13. Measured peak gain and radiation efficiency of the antenna.

and shown in Fig. 13. In this figure, the gain is measured in both the planes of the radiation pattern and the peak gain is selected from either plane which gives the larger value. The antennas have moderate gain with variations $<5 \mathrm{dBi}$ throughout the operating band, while the gain drops up to $-8 \mathrm{dBi}$ in the other frequencies. The efficiency of the antenna for both ports is measured using the Wheeler cap method and is also incorporated in Fig. 13. The antenna provides efficiency better than $70 \%$ in the bands of $2.5 \mathrm{GHz}, 3.6 \mathrm{GHz}$ and $5.3 \mathrm{GHz}$ and it drops to $50 \%$ in the notch band at $5.5 \mathrm{GHz}$.

\section{Time Domain Analysis}

To analyze the signal dispersion, the group delay is simulated between two identical antennas in the face-toface orientations, with a distance of $300 \mathrm{~mm}$ between them, which obtains the far-field condition of the antenna. As shown in Fig. 14, the group delay is about $1 \mathrm{~ns}$ across the frequency band except in the notched bands for various states, due to the band-notched function. For the rest of the frequency band, the group delay characteristic is relatively flat, indicating that the antennas have good linear transmission performances.

As the UWB communication has been based on impulse radio, it is necessary to consider the impulse distortion of the time-domain response of the proposed antenna. In telecommunication systems, the correlation between the input and output signals is evaluated using the fidelity factor $(F)$ [3],

$$
F=\max _{\tau}\left|\frac{\int_{-\infty}^{+\infty} s(t) r(t-\tau) \mathrm{d} \tau}{\sqrt{\int_{-\infty}^{+\infty} s(t)^{2} \mathrm{~d} t \cdot \int_{-\infty}^{+\infty} r(t)^{2} \mathrm{~d} t}}\right|
$$

where $s(t)$ and $r(t)$ are the input and output signals, respectively. To calculate the fidelity factor of the proposed dualband notched UWB antenna, it is assumed that the two 


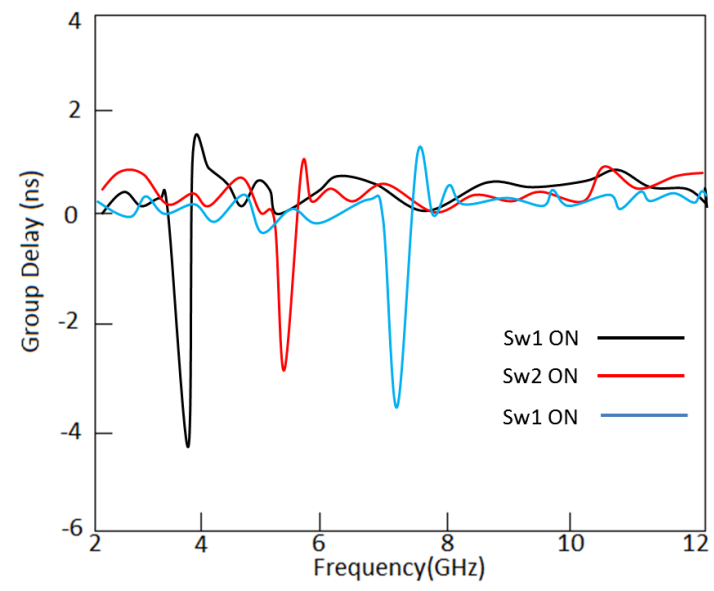

Fig. 14. Simulated group delay of the proposed antenna in the various states.

proposed antennas in Fig. 1 play the role of the transmitting antenna and receiving antenna. The two antennas are aligned pointing face-to-face and side-by-side orientations with a distance of $300 \mathrm{~mm}$. The input signal $s(t)$ formed of the Gaussian pulse can be excited to the transmitting antenna, then the received pulse signal $r(t)$ can be obtained to the receiving antenna. This pulse simulation is performed by a CST Design Studio simulator. By substituting the two normalized pulse signal in (6), we can calculate the fidelity factor $F$ which is the maximum correlation coefficient between two pulse signals. The antenna having $F=1$ indicates a perfect match between $s(t)$ and $r(t)$, without distortion in the transmission system of the pulse signal. The fidelity factor $F$ of the proposed dual-band notched UWB antenna for the face-to-face and side-by-side configurations were obtained equal to 0.92 and 0.86 , respectively. Values of the fidelity factor show that the proposed UWB antenna exhibits a good time domain performance in the view of operating UWB communication systems.

\section{Conclusion}

In this paper a UWB antenna with the switchable single or dual bands notched in application frequency bands is presented. The proposed antenna generates bands of 2.85-14.4 GHz. In addition, by changing state of the switches, single or dual or triple band-notched in bands of WiMAX, C-band satellite, WLAN and X-band, can eliminate the interference between UWB frequency band and other existing wireless communication systems. The proposed antenna is small and has different operating ranges, and it is applicable in a variety of wireless systems.

\section{References}

[1] KALTEH, A.A., DADASH ZADEH, G.R., NASERMOGHADASI, M., et al. Ultra-wideband circular slot antenna with reconfigurable notch band function. IET Microwaves, Antennas and Propagation, 2012, vol. 6, no. 1, p. 108-112. DOI: 10.1049/iet-map.2011.0125
[2] FCC Spectrum Policy Task Force, Report of the Spectrum Efficiency Working Group. FCC, Tech. Rep., 2002.

[3] MIRMOSAEI, S. S., AFJEI, S. E., MEHRSHAHI, E., et al. A dual band-notched ultra-wideband monopole antenna with spiral-slots and folded SIR-DGS as notch band structures. International Journal of Microwave and Wireless Technologies, 2015, available on CJO2015. DOI: 10.1017/S175 9078715000719.

[4] SHARBATI, V., REZAEI, P., FAKHARIAN, M. M., et al. A switchable band-notched UWB antenna for cognitive radio applications. IETE Journal of Research, 2015, vol. 61, no. 4, p. $423-428$. DOI: $10.1080 / 03772063.2015 .1025108$

[5] FAKHARIAN, M. M., REZAEI, P., AZADI, A. A planar UWB bat-shaped monopole antenna with dual band-notched for WiMAX/WLAN/DSRC. Wireless Personal Communications, 2015, vol. 81, no. 2, p 881-891. DOI: 10.1007/s11277-014-2162-8

[6] LEE, D.-H., YANG, H.-Y., CHO, Y.-K. Design and analysis of tapered slot antenna with $3.5 / 5.5 \mathrm{GHz}$ band-notched characteristics. Progress In Electromagnetics Research B, 2013, vol. 56, p. 347-363. DOI: 10.2528/PIERB13092702

[7] LEE, D.-H., YANG, H.-Y., CHO, Y.-K. Tapered slot antenna with band-notched function for ultrawideband radios. IEEE Antennas and Wireless Propagation Letters, 2012, vol. 11, p. 682-685. DOI: 10.1109/LAWP.2012.2204718

[8] KOOHESTANI, M., PIRES, N., SKRIVERVIK, A.K., et al. Bandreject ultra-wideband monopole antenna using patch loading. Electronics Letters, 2012, vol. 48, no. 16, p. 974-975. DOI: 10.1049/el.2012.1771

[9] LIU, W. X., YIN, Y.-Z. Dual band-notched antenna with the parasitic strip for UWB. Progress in Electromagnetics Research Letters, 2011, vol. 25, p. 21-30. DOI: 10.2528/PIERL11052609

[10] SHARBATI, V., REZAeI, P., SHAHZADI, A., et al. A planar UWB antenna based on MB-OFDM applications with switchable dual band-notched for cognitive radio systems. International Journal of Microwave and Wireless Technologies, 2014, p. 1-8. DOI: $10.1017 / \mathrm{S} 1759078714001317$

[11] FAKHARIAN, M. M., REZAEI, P., OROUJI, A. A. A novel slot antenna with reconfigurable meander-slot DGS for cognitive radio applications. Applied Computational Electromagnetics Society Journal, 2015, vol. 30, no. 7, p. 748-753.

[12] ZHU, F.G., GAO, S., HO, A. T.S., et al. Multiple band-notched UWB antenna with band-rejected elements integrated in the feed line. IEEE Transactions on Antennas and Propagation, 2013, vol. 61 , no. 8, p. 3952-3960. DOI: 10.1109/TAP.2013.2260119

[13] MA, T.G., JENG, S.K. Planar miniature tapered-slot-fed annular slot antennas for ultra-wideband radios. IEEE Transactions on Antennas and Propagation, 2005, vol. 53, no. 3, p. 1194-1202. DOI: 10.1109/TAP. 2004.842648

[14] KIM, J.-Y., KIM, N., LEE, S., et al. Triple band-notched UWB monopole antenna with two resonator structures. Microwave and Optical Technology Letters, 2013, vol. 55, no. 1, p. 4-6. DOI: 10.1002/ mop. 27275

[15] MORADIKORDALIVAND, A., RAHMAN, T.A., EBRAHIMI, S., et al. An equivalent circuit model for broadband modified rectangular microstrip-fed monopole antenna. Wireless Personal Communications, 2014, vol. 77 , no. 2, p. 1363-1375. DOI: $10.1007 / \mathrm{s} 11277-013-1585-\mathrm{y}$

\section{About the Authors...}

Vahid SHARBATI was born in Gorgan, Iran, in 1986. He received the B.S. degree in Electrical Engineering from Mazandaran University, Sari, Iran, in 2009. Currently, he is 
working towards the M.S. degree in Communication Engineering from the Semnan University. His current interest is in reconfigurable microstrip antennas.

Pejman REZAEI was born in Tehran, Iran, in 1977. He received the B.S. degree in Electrical-Communication Engineering from Communication Faculty, Tehran, Iran, in 2000, and the M.S. and Ph.D. degrees from Tarbiat Modarres University, Tehran, Iran, in 2002 and 2007, respectively. Currently, he is an assistant professor in the Semnan University, Semnan, Iran. His current research interests are electromagnetics theory, theory and design of antenna, metamaterial structure, and satellite communication.
Mohammad M. FAKHARIAN was born in Tehran, Iran, in 1987. He received the B.S. and M.S. degrees in Electrical Engineering from Semnan University, Semnan, Iran, in 2009 and 2012, respectively. Currently, he is working towards the Ph.D. degree in Communication Engineering from the Semnan University. His research interests include low-profile printed and patch antennas for wireless communication, fractal, miniature and multiband antennas, meta-materials and EBG structures interaction with antennas and RF passive components, reconfigurable antennas, and electromagnetic theory: numerical methods and optimization techniques. 